\title{
Interference with Social Activities
}

National Cancer Institute

\section{Source}

National Cancer Institute. Interference with Social Activities. NCI Thesaurus. Code

C110989.

The act of impeding a person from their normal social activities. 